\title{
Impacts of climate change on hydrological regimes in the Jinsha River Basin, China
}

\author{
Xiaopei $\mathrm{Ju}^{1}$, Yuankun Wang ${ }^{1}$, Dong $\mathrm{Wang}^{1}$, Jichun $\mathrm{Wu}^{1}$, Yuwei Tao ${ }^{1}$, and Rujian Qiu ${ }^{1}$ \\ ${ }^{1}$ Nanjing University
}

November 4, 2020

\begin{abstract}
The flow regime is of vital importance for the sustainable development of both human society and aquatic biota. Alterations in natural streamflow will modify the stability and biophysical distribution of river conditions, causing a series of adverse ecological and economic consequences. Climate change has been proven to pose potential threats to ecosystems; however, few studies have been conducted to quantify the variations between the flow regime of a future period and pristine natural flow specifically. This study investigates the future impacts induced by the changing climate in the Jinsha River Basin, which is known as the "Asian Water Tower" due to its rich hydroelectric energy resources. The SWAT model is used and calibrated to predict future streamflow. Seven GCMs from NASA NEX-GDDP with one ensemble average under two RCPs (RCP4.5 and RCP8.5) are used for both the NFP (2040s) and the FFP (2080s). The Indicators of Hydrologic Alteration (IHA) software and the river regime index (RRI) are used to assess the potential flow alterations of the Jinsha River. The results show that Pr, Tmax and Tmin all denote increasing trends, with the temperature trends being more obvious. For interannual alterations in flow regimes, most IHA values show moderate and high changes in all predicted conditions. In regard to the intra-annual changes, the results of the RRI show that river flow tends to be more concentrated in wet seasons than in cold seasons and denote evident seasonality and transience with advanced overall peaks of the river system. These findings together indicate that the flow patterns may have noticeable changes corresponding to the natural river regime.
\end{abstract}

\section{Impacts of climate change on hydrological regimes in the Jinsha River Basin, China}

Xiaopei $\mathrm{Ju}^{1}$, Yuankun Wang ${ }^{1 *}$, Dong Wang ${ }^{1}$, Jichun $\mathrm{Wu}^{1}$, Yuwei Tao ${ }^{1}$, Rujian $\mathrm{Qiu}^{1}$

1. Key Laboratory of Surficial Geochemistry, Ministry of Education, Department of Hydrosciences, School of Earth Sciences and Engineering, State Key Laboratory of Pollution Control and Resource Reuse, Nanjing University, Nanjing, PR China.

Corresponding Author: Yuankun Wang (yuankunw@nju.edu.cn)

Keywords: Climate change; SWAT; Indicators of Hydrologic Alteration; River regime index; Hydrological regimes; Jinsha River

\section{PLAIN SUMMARY}

This study concerns the comparative changes between the future and natural hydrological conditions caused by the changing climate in the Jinsha River Basin (JRB), China. To achieve this objective, (1) firstly, seven Global Climate Models (GCM) under two Representative Concentration Pathways (RCPs) were used to project the future climate variables; (2) then, the Soil and Water Assessment Tool (SWAT) hydrological model was employed and verified apt to predict future streamflow; (3) finally, the joint assessment of the Indicator of Hydrological Alterations (IHA) and the River Regime Index (RRI) was performed to investigate the potential variations of hydrological regimes under both interannual and intraannual scales. The increasing trends of both precipitation, maximum air temperature, and minimum air temperature can be found. In 
regard to the hydrological regimes, the projected runoff will be more centralized in summer and autumn. Extreme hydrological phenomena would occur more frequent in the future, and the flow patterns may have noticeable changes corresponding to the natural river regime. The results would assist both water managers and decision-makers in implementing the rational planning of hydraulic structures, as well as other management policies, to avoid potential risks.

RUNNING HEAD: Future hydrological regime changes

\section{ACKNOWLEDGEMENTS}

This study was supported by the National Key Research and Development Program of China (2017YFC1502704), and the National Natural Science Fund of China (51679118, 41571017, and 91647203), and Jiangsu Province" 333 Project" (BRA2018060).

\section{Hosted file}

Maintext.pdf available at https://authorea.com/users/372922/articles/490753-impacts-ofclimate-change-on-hydrological-regimes-in-the-jinsha-river-basin-china

\section{Hosted file}

Table.pdf available at https://authorea.com/users/372922/articles/490753-impacts-of-climatechange-on-hydrological-regimes-in-the-jinsha-river-basin-china

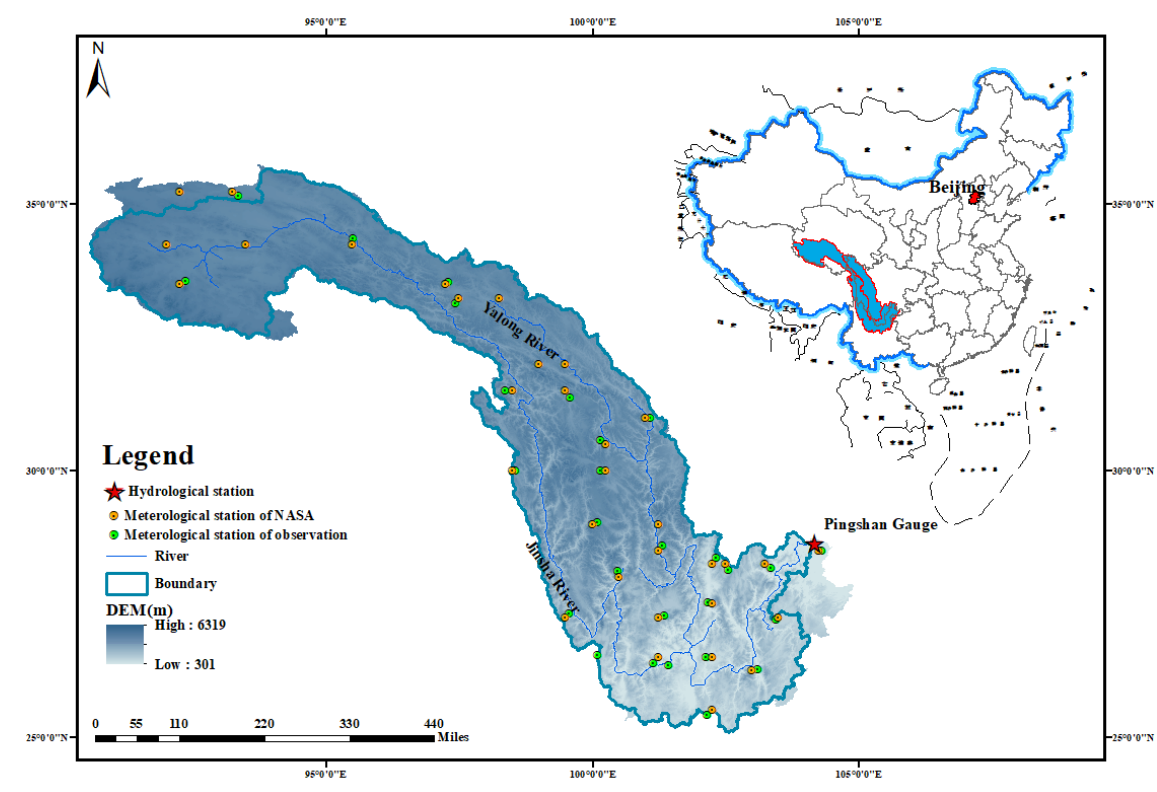



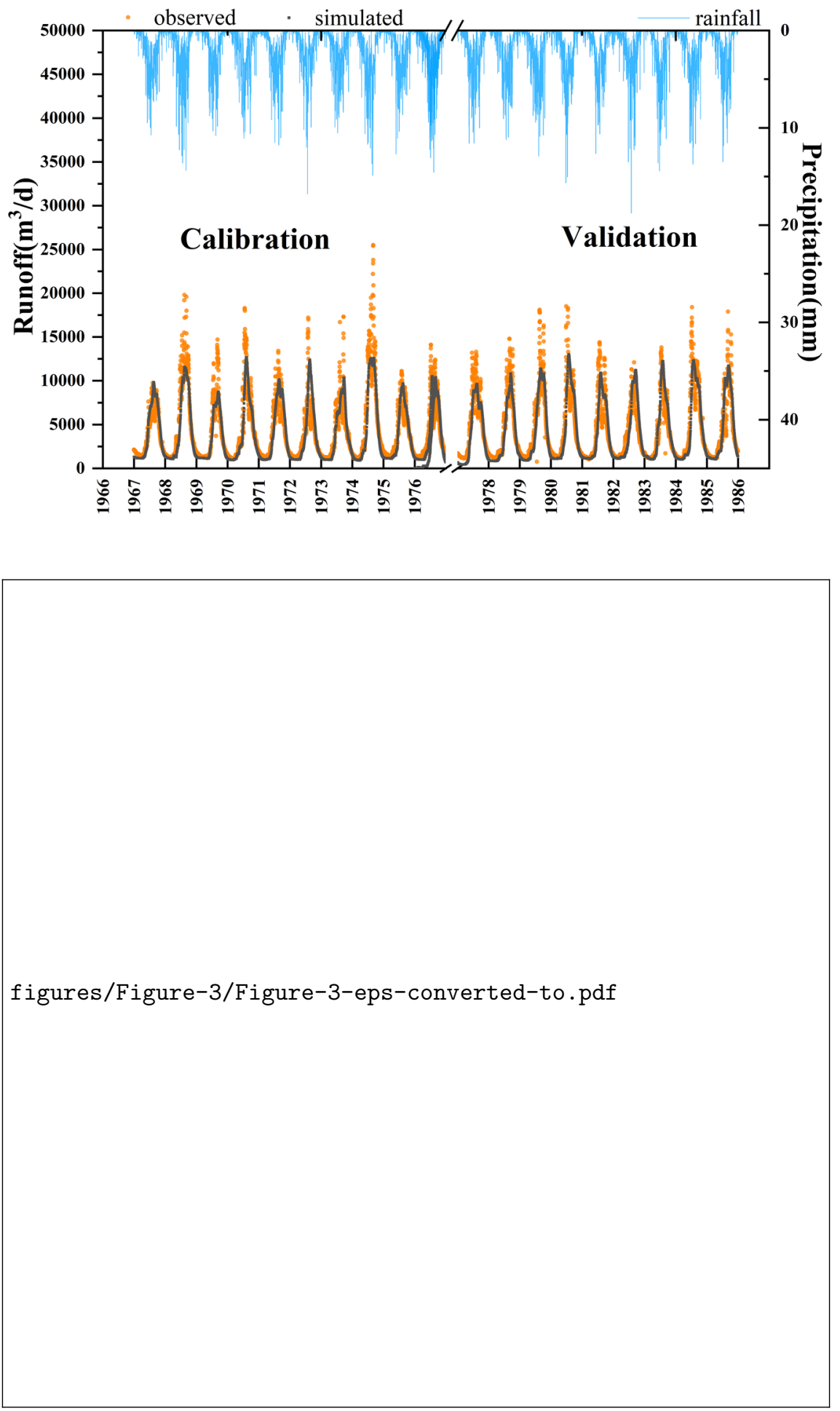
figures/Figure-4/Figure-4-eps-converted-to.pdf 
figures/Figure-5/Figure-5-eps-converted-to.pdf 
figures/Figure-6/Figure-6-eps-converted-to.pdf

\section{Hosted file}

Figure_7.eps available at https://authorea.com/users/372922/articles/490753-impacts-ofclimate-change-on-hydrological-regimes-in-the-jinsha-river-basin-china 